\title{
On the errors involved in ice-thickness estimates II: errors in digital elevation models of ice thickness
}

\author{
J. J. LAPAZARAN, ${ }^{1}$ J. OTERO, ${ }^{1}$ A. MARTÍN-ESPAÑOL, ${ }^{1,2}{ }^{2}$ F. J. NAVARRO ${ }^{1}$ \\ ${ }^{1}$ Departamento de Matemática Aplicada a las Tecnologías de la Información y las Comunicaciones, E.T.S.I. de \\ Telecomunicación, Universidad Politécnica de Madrid, Av. Complutense, 30, ES-28040 Madrid, Spain \\ ${ }^{2}$ Bristol Glaciology Centre, School of Geographical Sciences, University of Bristol, University Road, Bristol BS8 1SS, UK \\ Correspondence: J. J. Lapazaran <javier.lapazaran@upm.es>
}

\begin{abstract}
This paper is the second (Paper II) in a set of studies concerning the errors involved in the estimate of ice thickness and ice volume. Here we present a detailed analysis of the errors involved in the generation of ice-thickness DEMs constructed, most often, from GPR data, complemented by boundary data and sometimes, additional synthetic data arising from estimates based on theoretical considerations supported by independent data. We describe a complete methodology of error analysis that, starting from the errors in the data, propagates them to the grid nodes. In turn, the interpolation error at the grid nodes is calculated using a novel procedure that also provides an estimate of the bias introduced by the interpolation process. Finally, both errors are combined at the grid nodes to produce a gridpoint-dependent error estimate, which is complemented by an overall error estimate providing an assessment of the quality of the DEM. This methodology is illustrated with the case study of Werenskioldbreen, a land-terminating polythermal glacier in Svalbard.
\end{abstract}

KEYWORDS: DEM, error analysis, ground-penetrating radar, glacier mapping, ice thickness

\section{LIST OF MAIN SYMBOLS}

$H \quad$ Ice thickness

A Area of the glacier/ice sheet

$p \quad$ Fraction of $A$ quantifying the error in area of $A$

$\varepsilon_{H_{\text {DEM }}}$ Ice-thickness error of the DEM (mean value)

$\varepsilon_{H_{k}} \quad$ Ice-thickness error associated to the $k$-th grid node

$\varepsilon_{\text {Hint }_{k}} \quad$ Error of ice-thickness interpolation at the $k$-th grid node

$\varepsilon_{H \text { datak }}$ Ice-thickness error of the data at $k$-th grid node, propagated from the data points

$\varepsilon_{\text {Hdata }_{i}}$ Ice-thickness error for the $i$-th data point. Combines the effects of $\varepsilon_{H_{i}}$ and $\varepsilon_{H x y_{i}}$

$\varepsilon_{H_{i}} \quad$ Error in the value of ice thickness for the $i$-th data point (in Paper I, this was denoted $\varepsilon_{H \mathrm{GPR}_{i}}$ for the particular case of GPR data)

$\varepsilon_{H x y_{i}} \quad$ Error in ice thickness for the $i$-th data point due to the error in horizontal positioning, $\varepsilon_{x y_{i}}$

$\varepsilon_{x y_{i}} \quad$ Error in horizontal positioning for the $i$-th data point

$R \quad$ Radius of the largest circle devoid of data, i.e. the maximum possible distance from any point within the boundary to its nearest data point

DBF Distance-Bias Function

DEF Distance-Error Function

\section{INTRODUCTION}

The applications of ice-thickness DEMs are diverse. They are commonly used for geometry and volume assessment studies (e.g. Pettersson and others, 2011; Fischer and Kuhn, 2013; Lapazaran and others, 2013; Martín-Español and others,
2013; Ai and others, 2014; Navarro and others, 2014) and for ice dynamics modelling (e.g. Otero and others, 2010; Sugiyama and others, 2015; Wilkens and others, 2015). It is, therefore, of considerable importance that DEMs used to underpin any of these objectives are adjoined with the most complete possible assessments of their errors. There have been previous studies analysing the accuracy and some error sources of ice-thickness DEMs (e.g. Pettersson and others, 2011; Bamber and others, 2013; Fischer and Kuhn, 2013; Farinotti and others, 2014). However, we believe that a systematic study of the errors of DEMs of ice thickness is still lacking.

The aim of this study is to systematize the analysis and estimate of the errors involved in the construction of an icethickness DEM, taking into account their different sources. On one hand, we study the error in ice-thickness data (data error) and how it propagates to the nodes of the regular grid of a DEM. We consider ice-thickness data collected by any means, for example GPR, seismic prospecting, ice drilling, or even estimated on the basis of theoretical considerations, perhaps supported by independent field data. Following the rationale of the previous companion paper (Lapazaran and others, 2016; this issue (Paper I)), the data error is computed from those of its two components: the error in the value of the ice thickness and the error in ice thickness associated with the uncertainty in the datum's position (Fig. 1). The data error is then propagated to the grid points. On the other hand, we calculate the error due to the interpolation of these data to the grid points (interpolation error). Then, the propagated data error and the interpolation error are combined at the grid points of the DEM to produce the gridpoint-dependent error in ice thickness. A global error in ice thickness of the DEM is finally obtained from the errors 


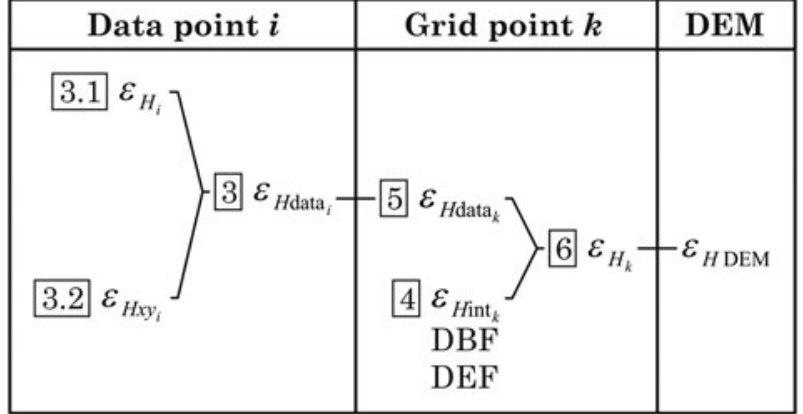

Fig. 1. Schematics of the splitting into error components followed in this study (see associated list of symbols). The numbering in the rectangles refers to the sections of this paper where each error component is discussed.

at the grid nodes, as a parameter to characterize the overall quality of the DEM.

In this paper we follow the basic terminology on errors described in Paper I. We take into account some error sources that are usually not considered in the literature, such as the error due to the uncertainty in the boundary of the ice mass. Additionally, we introduce a novel method to estimate the interpolation error, as well as a novel technique to transmit the data errors to the grid nodes of the DEM.

\section{HORIZONTAL RESOLUTION}

Although our main aim is to estimate the error in ice thickness of a DEM, the horizontal resolution of the DEM provides an indication of its quality and thus deserves some attention. We start by noting that both the density of ice-thickness data and the horizontal resolution at each data point contribute to the horizontal resolution of the DEM, although the grid size acts as a lower bound of the horizontal resolution.

As discussed in Paper I, the horizontal resolution of GPR data along profiles depends on whether the radargrams have been migrated or not. For non-migrated data, the horizontal resolution depends on the ice thickness, while for migrated data it does not. However, 2-D migration only corrects the data along the profiling direction, so the resolution in the direction perpendicular to the profile is unaffected by migration. Moreover, in the case of GPR there is a high data density along the profiles, while the zones between radar profiles, often large, are devoid of data. Consequently, the horizontal resolution of the ice-thickness DEM will not be uniform. It will be limited by the spacing between radar traces, by the spacing between radar profiles, by the depthdependent Fresnel radius (non-migrated profiles) or by $\lambda / 2$ (migrated profiles, with $\lambda$ the wavelength of the central frequency of the radar), and by the grid size of the DEM. Following Welch and others' (1998) arguments, even if all the field and processing techniques are properly applied, the maximum horizontal resolution of the DEM will be of $\lambda / 2 \times \lambda / 2$

\section{DATA ERROR}

Following Paper I, we consider errors in ice-thickness data, whatever their source is (see classification below), as made up of two components: the error in the value of ice thickness
$\left(\varepsilon_{H_{i}}\right)$, and the error in thickness due to the uncertainty in horizontal positioning of the datum $\left(\varepsilon_{H x y_{i}}\right)$. Since $\varepsilon_{H_{i}}$ and $\varepsilon_{H x y_{i}}$ are independent of each other, the error in thickness at a given data point is obtained by

$$
\varepsilon_{H_{\text {data }} i}=\sqrt{\varepsilon_{H_{i}}^{2}+\varepsilon_{H x y_{i}}^{2}} \text {. }
$$

Here, we classify ice-thickness sources for DEM generation into three types with differing error components as follows:

(1) 'Direct' ice-thickness measurements.

(2) Ice-boundary points with known zero ice thickness (e.g. front of land-terminating glaciers or contact of the glacier with its sidewalls).

(3) Indirect estimates of ice thickness at zones without direct ice-thickness measurements. We refer to these as 'synthetic' data.

We now separately analyse both error components for each ice-thickness-data type.

\subsection{Error in the value of ice thickness}

Ice-thickness measurements are the first of the three data types used to build the DEM. The particular case of GPR data was already discussed in Paper I. For ice-thickness measurements obtained from other techniques, similar studies will be required.

The second type of data is the ice boundary points with zero ice thickness assigned. In this case, the error in the value of ice thickness, $\varepsilon_{H_{i}}$, should be zero and the only uncertainty left is the error in thickness due to the error in horizontal positioning, $\varepsilon_{H x y_{i}}$, which we will discuss later.

The third type of ice-thickness data does not correspond to measurements but to estimates based on some kind of theoretical consideration, usually supported by independent field data. These synthetic data must also be accompanied by their error estimates, which will depend on the particular technique used for the estimation. For instance, the ice thickness of a non-surveyed tributary glacier, if computed by interpolation using only the zero-thickness boundary points at the contact of the tributary glacier with its sidewalls, would clearly produce an underestimate of the ice thickness. This can be improved by the use of techniques such as described in Navarro and others (2014). Other suggestions of use of such kind of data from estimates can be found in Fischer and Kuhn (2013) or in Fretwell and others (2013). The icethickness data provided by techniques based on the fulfilment of mass conservation between largely spaced radar profiles (e.g. Morlighem and others, 2011) could also be catalogued within this data type.

\subsection{Positioning-related ice-thickness error}

In Paper I we presented a method to estimate, for GPR measurements, the positioning-related ice-thickness error, $\varepsilon_{H x y_{i}}$, from estimates of the uncertainty in position, $\varepsilon_{x y_{i}}$. The same procedure can be followed to estimate $\varepsilon_{H x y_{i}}$ from other icethickness data sources, such as seismic or gravity measurements. The uncertainty in the position $\varepsilon_{x y_{i}}$ of the boundary data deserves particular attention, and is discussed in the following subsection. 
In the case of using synthetic ice-thickness data, uncertainty in position, $\varepsilon_{x y_{i}}$ will depend on the theoretical assumptions made to generate them. For instance, if the estimates depend on the distance to the nearest measurements or to the ice-mass boundary, they will also be affected by the uncertainty in position inherent to these nearest measurements or ice-mass boundary.

Once the uncertainty in position $\varepsilon_{x y_{i}}$ is known, we estimate the positioning-related ice-thickness error as the maximum discrepancy found (absolute value) between the value at the data point and the neighbouring values within a circle of radius $\varepsilon_{x y_{i}}$ using a DEM of ice thickness. The smoothing effect introduced by the DEM is compensated by the use of the maximum value.

\subsubsection{Boundary-positioning error}

The ice-mass boundary can include zero and non-zero icethickness data. We consider that the zero thickness assigned to boundaries separating ice and ground is free from error in the value of ice thickness, $\varepsilon_{H_{i}}$, provided that we take into account, separately, the positioning-related ice-thickness error, $\varepsilon_{H x y_{i}}$. However, at boundary points with non-zero ice-thickness, such as calving fronts, ice divides or artificial sections introduced in the ice to limit the modelling to a particular area, we take into account both the error in the value of ice thickness and the positioning-related ice-thickness error.

In the case of having detailed information on the uncertainty in a certain boundary delineation (e.g. Bernard and others, 2014), the estimate of $\varepsilon_{H x y_{i}}$ can be applied at the boundary on a point-by-point basis, using the individual $\varepsilon_{x y_{i}}$ for each boundary point. However, for ice boundaries in which a rough statistical estimate of the error in area is available, we propose to uniformly distribute the uncertainty in area, assigning a common uncertainty to all the boundary points, as shown in Figure 2. It is customary to characterize the uncertainty in boundary position in such cases as a fraction of area, $p$, of the total area, $A$ (so $p A$ represents the uncertainty in area, and $p / 100$ represents the percentage of error in area) (e.g. Bolch and others, 2010; Gjermundsen and others, 2011; Nuth and others, 2013; Paul and others, 2013; Pfeffer and others, 2014).

To estimate the corresponding horizontal uncertainty $\left(\varepsilon_{x y}\right.$ in Fig. 2) we use the Straight Skeleton routine of the

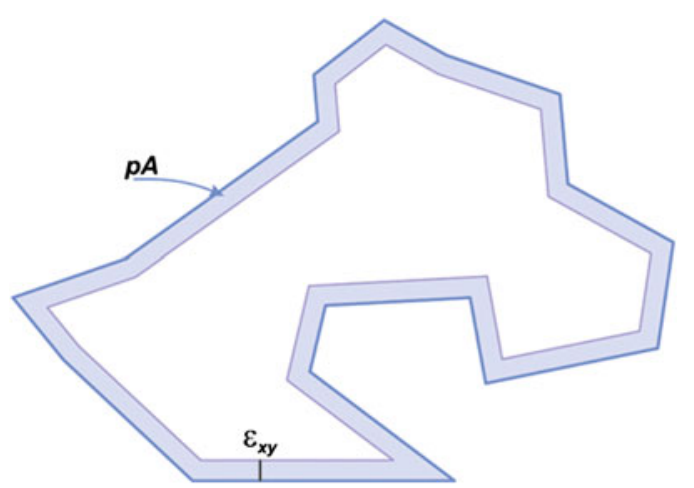

Fig. 2. The external polygon represents an ice boundary with area $A$. The uncertainty in area is assumed to be characterized by means of a fraction $p$ of its total area. The width of the blue-coloured internal band, $\varepsilon_{x y}$, is chosen so that the area of the band equals $p A$. This width is used as $\varepsilon_{x y_{i}}$ for the boundary points.
Computational Geometry Algorithms Library (CGAL) version 4.6, http://www.cgal.org/, distributed under the GPL/LGPL open source license. We obtain the horizontal uncertainty $\varepsilon_{x y_{i}}$ to be applied to every boundary point by letting the width of the blue-coloured internal band grow until its area reaches the total error in area, $p A$.

\section{ICE-THICKNESS INTERPOLATION ERROR}

The construction of ice-thickness DEMs involves the interpolation of ice-thickness data to a regular grid. This operation introduces an interpolation error, which will depend on the quantity and distribution of the field data available. The interpolation error at each grid point $k$ will be characterized as $\varepsilon_{\text {Hint }_{k}}$. In this study we assume that any extrapolation is avoided. We also assume that the interpolation method used is of weighted-average type (e.g. kriging, splines or inverse distance weighting), because these weights will be used to propagate the errors from the data points to the grid points. In cases using other types of interpolation, such as the approach based on completing the sparse GPR data using mass conservation (e.g. Farinotti and others, 2009a, b, 2014; Morlighem and others, 2011, 2013) or other techniques (e.g. Binder and others, 2009; Herzfeld and others, 2011), some parts of our error study should be adapted accordingly.

Different approaches have been followed in the literature to infer the interpolation error. In the case of kriging interpolation, it is well known that the kriging variance underestimates the interpolation error (e.g. Journel, 1986; Cressie, 1993, p. 127; Chainey and Stuart, 1998; den Hertog and others, 2006; Rotschky and others, 2007), although it has been used in glaciology to evaluate the accuracy of the interpolated values (e.g. Bamber and others, 2001). Some authors evaluate the uncertainties by comparing the DEMs resulting from different subsets of GPR data (e.g. Fischer, 2009), or bootstrapping methods (e.g. den Hertog and others, 2006; Bamber and others, 2013). Another commonly used technique to assess the statistical interpolation is the cross validation (Cressie, 1993). Following the cross-validation concept some authors have removed one datum at a time (leave-oneout cross validation, e.g. Pettersson and others, 2003, 2011; Koppes and others, 2009; Lindbäck and others, 2014). However, when dealing with GPR data, with profiles that are usually irregularly distributed, cross-validation risks incorrectly inferring the interpolation error in areas where measurements are dense, leading to a systematic underestimation of the interpolation error. Trying to solve this problem, Fretwell and others (2013) split the data into two subsets, using one subset to cross validate the other and vice versa. More recently, Farinotti and others (2014) solved this underestimation problem using a cross-validation-based method that removes sets of GPR profiles from the whole dataset and evaluates the error expressed as a function of the distance to the nearest GPR point.

We propose a novel method to evaluate the interpolation error, suitable for any type of data, including sparse and uneven data distributions typical of for example GPR or seismic profiling, or bathymetric studies. Our method assesses the interpolation error at any point by measuring the random-variable interpolation-error at the data points (difference between predicted and measured values) using a cross-validation technique that only considers neighbouring data located beyond a given radius (blanking radius) 


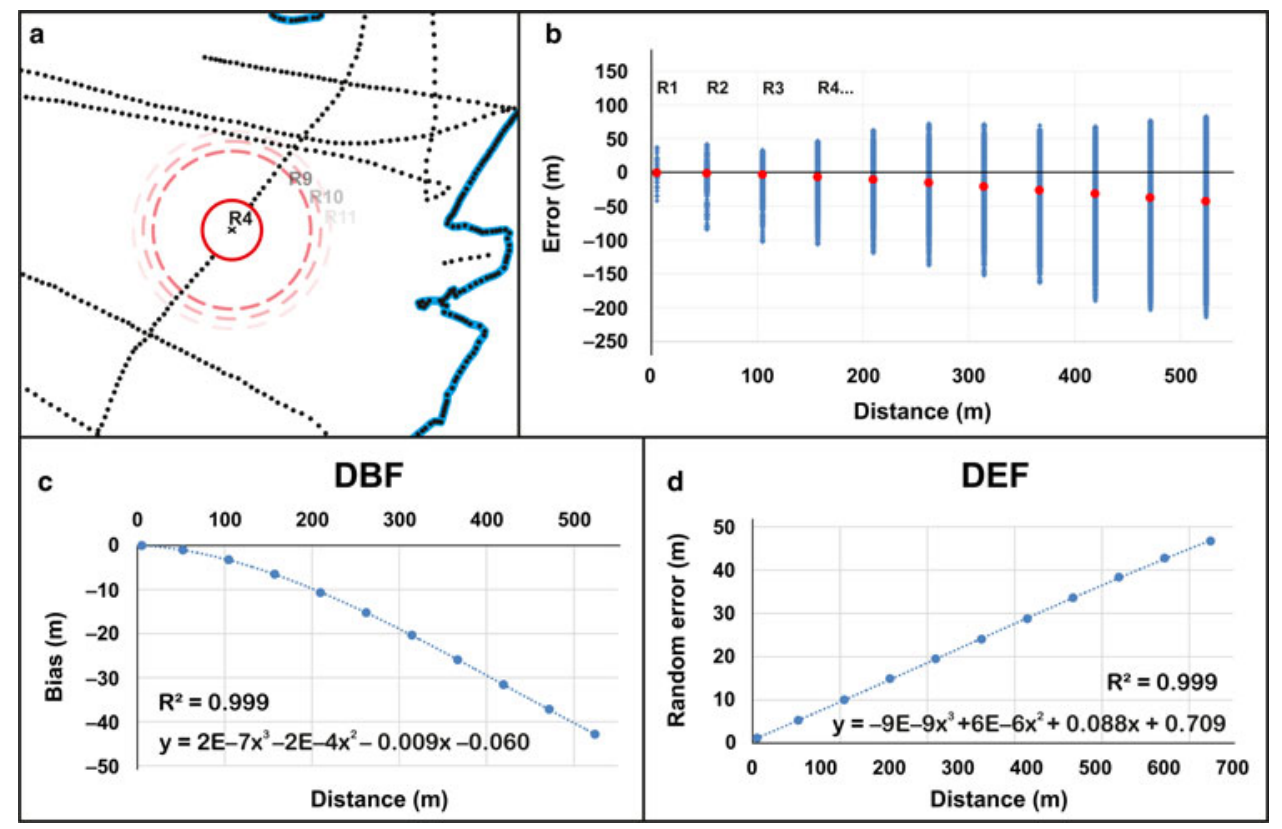

Fig. 3. Steps of the process of estimating and applying the DBF and the DEF to Werenskioldbreen. (a) Sequence of blanking circles around a data point, with increasing radii ... $R_{4} \ldots R_{9}, R_{10}, R_{11}$, of which $R_{4}$ is the blanking circle currently applied; the blue curves represent ice boundaries and the black dots represent points where ice-thickness data are available. (b) Distributions of the interpolation error for each blanking radius; both the negative bias (mean values, in red) and the random error of the distributions grow with the blanking radius. (c) DBF obtained by least-squares fitting of the mean values of the distributions of interpolation error. (d) DEF obtained by least-squares fitting of the standard deviations of the distributions of interpolation error.

from this data point (Fig. 3a). This technique consists of four stages, split into seven steps in the algorithm described below. In the first stage, we measure the interpolation error at every data point for a set of blanking radii with increasing size. In the second stage we compute, for each blanking radius, a possible interpolation bias (mean error) and the standard deviation (characterizing the random error) of the corresponding random-variable interpolation-error (Fig. 3b). In the third stage we fit, by least squares, corresponding functions both to the bias and to the standard deviations of the measured interpolation errors. These functions, named Distance-Bias Function (DBF) and Distance-Error Function (DEF) (Figs 3c, d) relate, at any given point, the bias and the interpolation random error (standard deviation) with the distance to the nearest data point (details in algorithm steps below). Finally, in the fourth stage we apply these functions to each grid point $k$, taking into account its distance to the nearest data point. We do it by first correcting the thickness value with the assessed bias using the DBF, and then assigning the error to the resulting value using the DEF, thus obtaining $\varepsilon_{\text {Hint }_{k}}$.

Starting from a dataset made up of ice-thickness measurements, boundary points (zero- and non-zero-thickness points), and any other possible synthetic data, the steps of the algorithm proceed as follows:

(1) Calculate $R$, the radius of the largest zone devoid of data in the dataset. $R$ represents the maximum possible distance from any point within the boundary to its nearest data point. Then take a sequence of radii of increasing size, $R_{1}, R_{2}, R_{3} \ldots$ starting with a tiny one and then stepping up to $R$ (e.g. 11 radii, $R / 100, R / 10,2 R / 10,3 R / 10 \ldots R$ ).

(2) Centre a blanking circle with radius $R_{1}$ at a data point (Fig. 3a). Using the data located outside the circle, interpolate the value at the centre of the blanking circle, and calculate the difference between the interpolated and the data values, thus obtaining the error of this interpolation. This is repeated for each data point, obtaining the distribution of the predicted error when the distance to the nearest datum is $R_{1}$. The boundary data points should be excluded from this process, to avoid extrapolation.

(3) The procedure is repeated using the various radii $R_{1}, R_{2}$, $R_{3} \ldots$ obtaining the distributions of the prediction error for the different distances to the nearest data points (Fig. 3b).

(4) For each $R_{i}$, calculate the mean errors (biases) and their standard deviations (random errors) (dots in Figs 3c, d).

(5) Generate a DBF by least-squares fitting of the pairs of $R_{i}$ versus bias, to a polynomial curve (Fig. 3c). At any given point, the DBF relates the bias of the interpolation method to the distance to the nearest data point.

(6) Generate a DEF by least-squares fitting of the pairs of $R_{i}$ versus random error, to a polynomial curve (Fig. $3 d$ ). At any given point, the DEF relates the interpolation random error to the distance to the nearest data point.

(7) Apply the DBF and the DEF to every nodal value of the interpolated grid. For each grid point, measure the distance to the nearest data point, add the bias (positive or negative) obtained using the DBF for this distance, and assign the interpolation error given by the DEF for this distance, $\varepsilon_{\text {Hint }_{k}}$ (the subscript $k$ is used to indicate grid nodes).

Although this method is based in the cross-validation concept, it solves the problem of error underestimation in dense data of the leave-one-out cross validation. The advantage of our method from previous strategies is that it does not depend on decisions about how to split the dataset, or which profiles must be left out and cross-validated. On the contrary, our method systematically estimates the interpolation errors at every data point for all the 
different distances to the nearest data point. Thus, our method makes optimal use of the information contained in the dataset, in a more consistent, robust and systematic way than previous methods.

\section{PROPAGATION OF THE ERROR IN THE DATA TO THE GRID NODES}

Ice-thickness DEMs are constructed by interpolating unevenly distributed ice-thickness measurements to a regular grid. Therefore, to assess the quality of the DEM the errors in ice thickness at the data points must be propagated to the grid nodes, and then combined with the interpolation errors at the grid nodes.

Assuming that a weighted-average interpolation method is used to build the ice-thickness DEM, the interpolated value of the ice thickness at a grid cell, $H_{k}$ is calculated as a weighted combination of the thicknesses at some (say $n$ ) neighbouring data points $H_{i}$, i.e. $H_{k}=\left(\sum_{i=1}^{n} w_{i} H_{i}\right)_{k^{\prime}}$ with $\sum_{i=1}^{n} w_{i}=1$. We propose calculating the error propagation from the data points to the grid nodes using the same weighted combination, but now applied to the errors instead of the ice thicknesses:

$$
\varepsilon_{\text {Hata }_{k}}=\left(\sum_{i=1}^{n} w_{i} \varepsilon_{\text {Hdata }_{i}}\right)_{k} .
$$

This implies an assumption of linear dependence between the error at the grid point and the errors at the neighbouring data points. Due to the unit summation of the weights, the error in the data propagated by Eqn (2) to a grid node is a weighted mean of the errors in the data involved. This is a reasonable approximation, conservative in most cases, as explained below.

Negative ice thicknesses are physically meaningless, so the interpolation scheme must preserve the positive values of the interpolated ice thickness. This can be achieved by using non-negative interpolation weights, such as positive kriging (e.g. Szidarovszky and others, 1987; Deutsch, 1996; Yamamoto, 2000).

Similarly to what we do in Eqn (2), Herzfeld (2004) proposed the use of the interpolation weights for the error propagation from the data points to the grid nodes in the case of kriging interpolation, but she used the root of the squared summation of the $n$ weighted neighbouring values $\varepsilon_{\text {Hdata }_{k}}=$ $\left(\sum_{i=1}^{n} w_{i}^{2} \varepsilon_{\text {Hdata }_{i}}^{2}\right)_{k}^{1 / 2}$ (as if these errors were independent), or, in a simplified version, using the RMS value of the neighbouring errors $\varepsilon_{\text {data }_{k}}=\left(\sum_{i=1}^{n} w_{i}^{2}\left(\sum_{i=1}^{n} \varepsilon_{\text {data }_{i}}^{2} / n\right)\right)_{k}^{1 / 2}$. However, this expression provides error propagation that does not average the surrounding data errors. If positive kriging is used, and taking into account the unit summation of the ordinary kriging weights, Herzfeld's assumption implies a decrease in the squared values of the weights, so this gives error estimates at the grid nodes much lower than those at surrounding data points, especially when $n$ is large. For instance, let us suppose that a dataset consists of four data points, all with the same value $H$ and the same error $E$, located at the corners of a square. If we interpolate at the centre of the square, we would expect to get $H$ as the interpolated value and $E$ as its error propagated to the central point. However, assigning a weight of 0.25 to each data point, the interpolated value is indeed $H$, but the propagated error obtained using the nonlinear method by Herzfeld is $0.5 E\left(\left[4\left(0.25^{2} E^{2}\right)\right]^{1 / 2}\right)$. If, instead, we use Eqn (2), then the error propagated to the central point is $E$. On the other hand, if not all the weights were positive, larger absolute values of the weights could be involved, still preserving the unit summation. This could imply very large errors at the grid nodes, even several times larger than those at the surrounding data points. For instance, using a similar dataset with four points as before, if the interpolation weights were for example $5,-6,10,-8$, the propagated error using again the non-linear method would be $15 E\left(\left(5^{2} E^{2}+6^{2} E^{2}+10^{2} E^{2}+8^{2} E^{2}\right)^{1 / 2}\right)$, while, using Eqn (2), the error propagated to the central point is again $E$.

Because of the above reasons, we are in favour of the linear approach involved in Eqn (2). No matter whether the interpolation weights used are positive or not, Eqn (2) provides, due to the unitary weight summation, an error at each grid point that averages those at the surrounding data points. We thus obtain a reasonable approximation, conservative in the case of using positive weights.

\section{ICE-THICKNESS ERROR OF THE DEM}

Propagation of the errors in the data to the grid nodes pro-

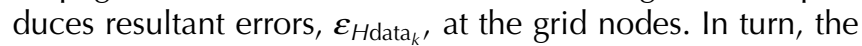
interpolation errors at the grid nodes, $\varepsilon_{\text {Hint }_{k}}$, can be estimated using the DEF. Assuming that in practice these errors can be considered independent, they can be combined as the root of their squared summation, obtaining the total ice-thickness error associated with each grid node,

$$
\varepsilon_{H_{k}}=\sqrt{\varepsilon_{\text {Hata }_{k}}^{2}+\varepsilon_{\text {Hint }_{k}}^{2}}
$$

The propagation of data errors to the grid nodes increases the spatial correlation of the associated errors, smoothing their variability. Consequently, the distribution of errors at the grid nodes will in general be narrower than the error distribution that would be obtained if the data were hypothetically located at the grid points.

Applying Eqn (3) to the grid nodes we obtain an error map of the DEM. However, sometimes it can be useful to characterize the overall quality of the ice-thickness DEM, using a single parameter, for example to estimate the ice-volume error (Martín-Español and others, 2016; this issue (Paper III)), to evaluate the overall quality of DEMs, or to compare their accuracy. In these cases, we can use the RMS value of the errors at the grid nodes,

$$
\varepsilon_{H \mathrm{DEM}}=\sqrt{\frac{1}{N} \sum_{k=1}^{N} \varepsilon_{H_{k}}^{2}},
$$

and this parameter will be less sensitive to the above-mentioned smoothing. Note, on the other hand, that the quality of an ice-thickness DEM cannot be calculated directly as the RMS of the errors in the data, because the data distribution, in particular in the case of GPR data, is uneven.

\section{CASE STUDY: WERENSKIOLDBREEN}

Following the above-discussed techniques, we here present a complete study of the errors for the DEM of ice thickness of 


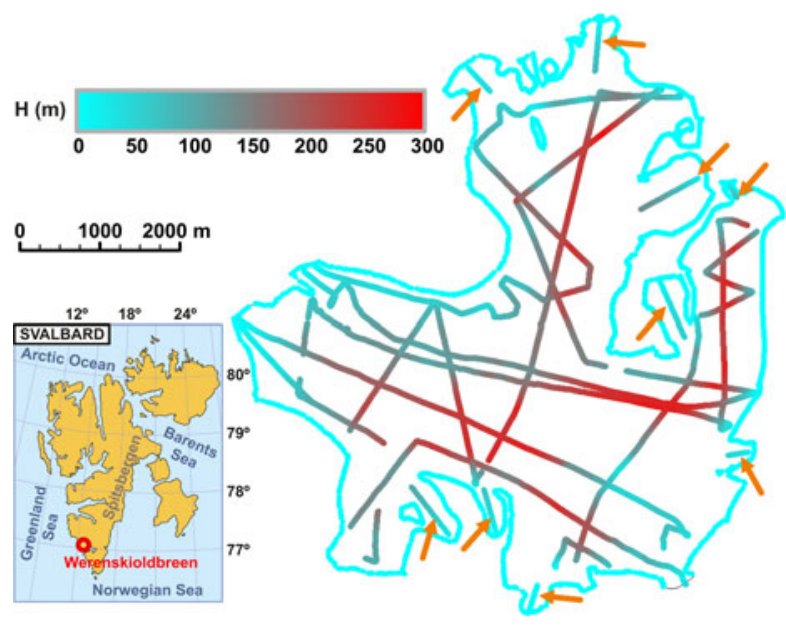

Fig. 4. Location of Werenskioldbreen in Svalbard and the dataset used to construct the ice-thickness DEM of Werenskioldbreen. The whole dataset of ice thickness is represented using colour scale and the ice divide with Tuvbreen is shown as a thin black curve in the south-east. The dataset is made of three different types of data: ice-thickness data obtained by means of GPR profiling, zero-icethickness boundary points and synthetic data estimated at some non-surveyed tributary glaciers (marked with orange arrows).

Werenskioldbreen, a land-terminating polythermal glacier in Svalbard (Fig. 4).

The maximum distance between glacier points is $\sim 7 \mathrm{~km}$, while the maximum distance between any grid point and its nearest data point is $\sim 525 \mathrm{~m}$, with a mean value of $\sim 100 \mathrm{~m}$. Thus, the coverage of the glacier surface by the GPR profiles is relatively dense, yet large areas remain devoid of data, as is usual with GPR profiling. This includes both large areas between distant GPR profiles and small non-surveyed tributary glaciers (in fact, small lateral glacier cirques supplying ice to the main glacier trunk). The details of the GPR survey, the data processing and the analysis of the associated errors can be found in Paper I. The ice thickness of the entire boundary is set to zero, except for the ice divide with Tuvbreen (a tributary of Hansbreen), to the south-east. By setting the boundary ice thickness to zero however, interpolation of ice thickness in the non-GPR-surveyed tributaries is biased towards unrealistically low values. To counter this issue, we therefore added to the ice-thickness dataset some additional ice-thickness data points obtained using a slightly modified version of the tributary thickness function for Svalbard glaciers described by
Navarro and others (2014). In our implementation of their method, we obtained regressions both for the normalized amplitudes and the normalized errors. Since, in the case of Werenskioldbreen GPR profiles, there are no measurements of ice thickness at the zones of confluence of the tributaries with the main trunk of the glacier, we increased quadratically the estimated errors by half of the estimated ice thickness. The entire ice-thickness dataset resulting from this addition of data is shown in Figure 4.

We interpolated the ice thickness of the glacier using ordinary kriging to a $50 \mathrm{~m} \times 50 \mathrm{~m}$ grid, and found no 2-D geometric anisotropy (e.g. Wackernagel, 2003). The resulting ice-thickness DEM is shown in Figure $5 \mathrm{a}$, and has a mean value of $107.65 \mathrm{~m}$, with standard deviation of $73.37 \mathrm{~m}$ and maximum gridded value of $276.71 \mathrm{~m}$. We calculated the distance-bias and distance-error functions as explained earlier. The results are shown in Figures 3c, d. The pointdependent interpolation bias applied to each of the grid points yields a DEM of bias, shown in Figure $5 b$ (mean value of $4.41 \mathrm{~m}$, standard deviation of $6.00 \mathrm{~m}$ and maximum value of $42.55 \mathrm{~m}$ ). The final, bias-corrected ice-thickness DEM of Werenskioldbreen, obtained as a point-by-point summation of the interpolated ice thickness and the interpolation bias, is shown in Figure 5c. It has a mean value of $112.31 \mathrm{~m}$, with standard deviation of $74.15 \mathrm{~m}$ and maximum gridded value of $277.00 \pm 7.24 \mathrm{~m}$ (error estimated as described later).

Let us now analyse the errors in the ice-thickness DEM. The errors in the value of the ice-thickness data, $\varepsilon_{H_{i}}$, are shown in Figure 6a. As discussed in Paper I, those corresponding to the GPR data were between $3.32 \mathrm{~m}$ (vertical resolution of the $25 \mathrm{MHz}$ radar) and $6.61 \mathrm{~m}$. To the zerothickness boundary points we assigned a zero error in the value of ice thickness (so all of their error in thickness will correspond to the error due to boundary uncertainty). The errors for the synthetic ice-thickness data points added at some tributaries using our modified version of the tributary thickness function of Navarro and others (2014), however, were much larger, up to $71.20 \mathrm{~m}$, due to the above-mentioned lack of GPR data at the zones of confluence of the tributaries with the main trunk of the glacier.

Figure $6 \mathrm{~b}$ shows the positioning-related ice-thickness error for each data point, $\varepsilon_{H x y_{i}}$. For the GPR measurement points, we estimated $\varepsilon_{H x y_{i}}$ as described in Paper I. To obtain the uncertainty in position at each boundary point, we adopted an $8 \%$ error in area (i.e. $p=0.08$ ) after Nuth and others (2013), which for Werenskioldbreen translates as an $\varepsilon_{x y_{i}}$ of $48 \mathrm{~m}$. The errors in ice thickness due to
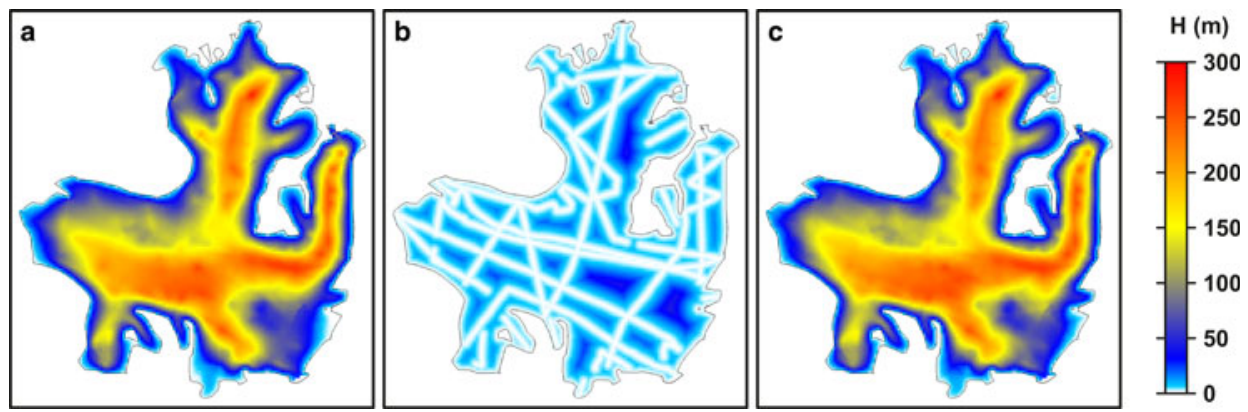

Fig. 5. DEM of ice thickness of Werenskioldbreen. The colour scale is common for the three panels. (a) DEM of ice thickness obtained by direct interpolation of the data. (b) DEM of interpolation bias obtained applying the DBF to the grid points. Since the bias is negative (Fig. 3c), it is shown with reversed sign, to use a common scale. (c) Final DEM of ice thickness of Werenskioldbreen, obtained as pointby-point summation of the DEMs in (a) and (b). 

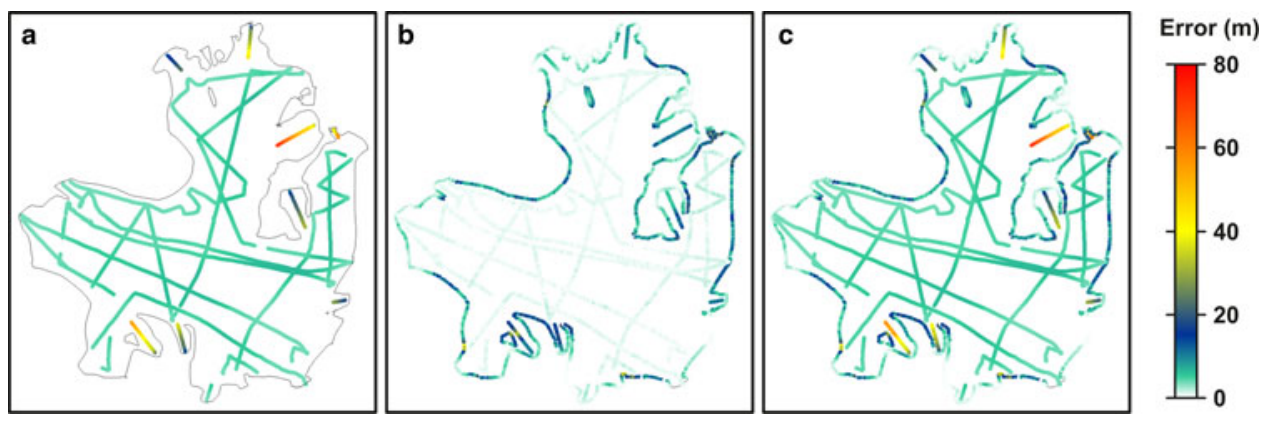

Fig. 6. Ice-thickness errors of the dataset. The colour scale is common for the three panels and for the next Figures. (a) Error in the value of ice thickness, $\varepsilon_{H_{i}}$ (boundary dots not shown, because of their zero error). (b) Error in ice-thickness due to the uncertainty in horizontal positioning, $\varepsilon_{H x y_{i}}$. (c) Error in ice thickness of the data, $\varepsilon_{H \text { data }_{i},}$ obtained as combination, using Eqn (1), of the errors shown in (a) and (b).
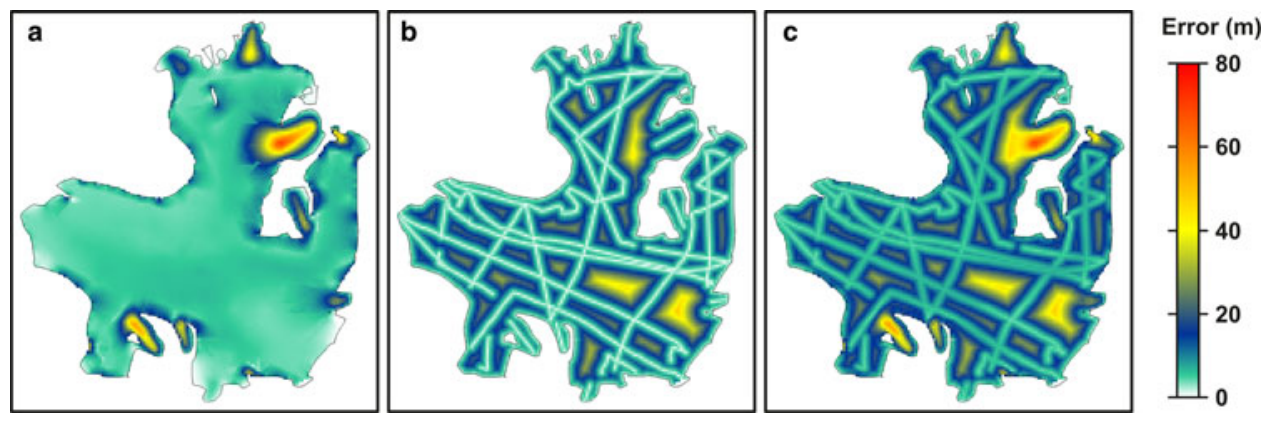

Fig. 7. (a) DEM of errors propagated from the data points to the grid points using Eqn (2). (b) DEM of interpolation errors at the grid points, obtained applying the DEF to every grid point. (c) Final DEM of error in ice thickness, associated with the DEM of ice thickness shown in Figure 5c.

uncertainty in position of the boundary have a mean value of $6.13 \mathrm{~m}$, with standard deviation of $5.75 \mathrm{~m}$ and a maximum value of $39.03 \mathrm{~m}$. Such errors at the boundary are much larger than those of GPR data, because the uncertainty in horizontal positioning and the gradient of ice thickness are both large at the glacier boundaries of Werenskioldbreen. Finally, we assigned to the synthetic ice-thickness values calculated at some tributaries, the same uncertainty in horizontal positioning as that of the boundary points $\left(\varepsilon_{x y}=48 \mathrm{~m}\right)$, because the positions of the estimated ice-thickness points in these tributaries were tied to the glacier boundaries. This implied positioning-related ice-thickness errors at the synthetic points in the tributaries reaching $35.32 \mathrm{~m}$ (mean value, $10.55 \mathrm{~m}$; standard deviation, $6.02 \mathrm{~m}$ ).

Figure $6 \mathrm{c}$ shows the error in ice thickness of the data, $\varepsilon_{\text {Hata }_{i}}$ obtained using Eqn (1), as combination of the errors in value, $\varepsilon_{H_{i}}$ (Fig. 6a) and those due to uncertainty in position, $\varepsilon_{H x y_{i}}$ (Fig. 6b).

We then propagated the errors in the data points to the grid points by means of Eqn (2), using the same weights of the kriging interpolation. Figure $7 \mathrm{a}$ shows the resulting DEM of propagated errors (mean value, $7.20 \mathrm{~m}$; standard deviation, $7.24 \mathrm{~m}$; maximum value, $69.02 \mathrm{~m}$ ). The interpolation errors, characterized by the DEF (Fig. $3 d$ ), were then applied to the grid points, producing the DEM of interpolation error shown in Figure $7 \mathrm{~b}$ (mean value, $9.93 \mathrm{~m}$; standard deviation, $7.82 \mathrm{~m}$; maximum value, $47.42 \mathrm{~m}$ ). Following Eqn (3), the resulting root of the squared summation of both previous DEMs, calculated point by point, is shown in Figure 7c (mean value, $13.41 \mathrm{~m}$; standard deviation, $9.17 \mathrm{~m}$; maximum value, $69.11 \mathrm{~m}$ ). It represents the final DEM of ice-thickness errors associated with the ice-thickness DEM of Werenskioldbreen shown in Figure 5c. Finally, we estimated the overall error of the DEM of ice thickness of Werenskioldbreen using Eqn (4), getting $\varepsilon_{H \text { DEM }}=16.24 \mathrm{~m}$.

\section{CONCLUSIONS}

We have developed a systematic methodology to estimate the error of a DEM of ice thickness. It splits the error into various independent components, which facilitates the estimate of the errors arising from different sources. The aim was to provide, together with the ice-thickness DEM, an individual error estimate at each of the grid nodes (getting a DEM of error in ice thickness), as well as an overall error estimate characterizing the quality of the ice-thickness DEM as a whole.

Starting from the error in the data (discussed, for GPR data, in Paper I), this error is propagated to the grid nodes of the DEM. In turn, the interpolation error at the grid nodes is also calculated. Both errors are then combined to get the error in ice thickness at each grid node. An error characterizing the overall quality of the DEM is finally computed.

The methodology described includes some novel techniques of error estimate:

(1) The method used to propagate the error in the data points to the grid points, based on a weighted linear approach that uses the same weights involved in the interpolation process of weighted-average type. 
(2) The method adopted to estimate the interpolation error at each grid node, which also allows detecting of and correcting for the bias introduced by the interpolation process. This is achieved by means of the DEF and DBF. The main advantage of this method compared with previous approaches is that it is systematic, more consistent and robust. It methodically estimates, at every data point, the interpolation errors for the various distances to the nearest data point associated with the different blanking radii, thus making optimal use of the information contained in the dataset.

(3) The method applied to estimate the positioning-related icethickness error. This was discussed, for the case of GPR data, in Paper I, but we extended it here to include the cases of boundary ice-thickness data and synthetic data.

This methodology of error estimate was applied to the case study of Werenskioldbreen, a land-terminating polythermal glacier in Svalbard. The interpolation error was shown to be a main source of error, though, in the particular case of Werenskioldbreen, the largest errors corresponded to the additional synthetic data estimated at the non-surveyed tributary glaciers.

\section{ACKNOWLEDGEMENTS}

We thank the scientific editor, Jo Jacka, and two anonymus reviewers for their valuable comments and suggestions, which helped to improve this paper. This research was supported by grants CTM2011-28980 and CTM2014-56473-R from the Spanish National Plan for R\&D. We thank Jacek Jania and Mariusz Grabiec (Faculty of Earth Sciences, University of Silesia), and Dariusz Puczko (Institute of Geophysics, Polish Academy of Sciences) for making available to us Werenskioldbreen GPR data.

\section{REFERENCES}

Ai S and 6 others (2014) Topography, ice thickness and ice volume of the glacier Pedersenbreen in Svalbard, using GPR and GPS. Pol. Res., 33, 18533 (doi: 10.3402/polar.v33.18533)

Bamber JL, Layberry RL and Gogineni SP (2001) A new ice thickness and bed data set for the Greenland ice sheet: 1. Measurement, data reduction, and errors. J. Geophys. Res., 106(D24), 3377333780 (doi: 10.1029/2001JD900054)

Bamber JL and 10 others (2013) A new bed elevation dataset for Greenland. Cryosphere, 7, 499-510 (doi: 10.5194/tc-7-4992013)

Bernard É and 5 others (2014) Where does a glacier end? GPR measurements to identify the limitsbetween valley slopes and actual glacier body. Application to the Austre Lovénbreen, Spitsbergen. Int. J. Appl. Earth Obs. Geoinf, 27, 100-108 (doi: 10.1016/j. jag.2013.07.006)

Binder D and 5 others (2009) Determination of total ice volume and ice-thickness distribution of two glaciers in the Hohe Tauern region, Eastern Alps, from GPR data. Ann. Glaciol., 50(51), 7179 (doi: 10.3189/172756409789097522)

Bolch T, Menounos B and Wheate R (2010) Landsat-based inventory of glaciers in western Canada, 1985-2005. Remote Sens. Environ., 114, 127-137 (doi: 10.1016/j.rse.2009.08.015)

Chainey S and Stuart N (1998) Stochastic simulation: an alternative interpolation technique for digital geographic information. In Carver S ed. Innovations in GIS 5: selected papers from the Fifth National Conference on GIS Research UK (GISRUK). Taylor \& Francis, London, 3-24 (doi: 10.1201/b16831-3)

Cressie N (1993) Statistics for Spatial Data, Revised edition. Wiley, New York, 900 p. den Hertog D, Kleijnen JPC and Siem AYD (2006) The correct Kriging variance estimated by bootstrapping. J. Oper. Res. Soc., 57, 400-409 (doi: 10.1057/palgrave.jors.2601997)

Deutsch CV (1996) Correcting for negative weights in ordinary kriging. Comput. Geosci., 22(7), 765-773 (doi: 10.1016/00983004(96)00005-2)

Farinotti D, Huss M, Bauder A, Funk M and Truffer M (2009a) A method to estimate ice volume and ice-thickness distribution of alpine glaciers. J. Glaciol., 55(191), 422-430 (doi: 10.3189/ 002214309788816759)

Farinotti D, Huss M, Bauder A and Funk M (2009b) An estimate of the glacier ice volume in the Swiss Alps. Global Planet. Change, 68(3), 225-231 (doi: 10.1016/j.gloplacha.2009.05.004)

Farinotti D, King E, Albrecht A, Huss M and Gudmundsson GH (2014) The bedrock topography of Starbuck Glacier, Antarctic Peninsula, as determined by radio-echo soundings and flow modeling. Ann. Glaciol., 55(67), 22-28 (doi: 10.3189/2014AoG67A025)

Fischer A (2009) Calculation of glacier volume from sparse ice-thickness data, applied to Schaufelferner, Austria. J. Glaciol., 55(191), 453-460 (doi: 10.3189/002214309788816740)

Fischer A and Kuhn M (2013) Ground-penetrating radar measurements of 64 Austrian glaciers between 1995 and 2010. Ann. Glaciol., 54(64), 179-188 (doi: 10.3189/2013AoG64A108)

Fretwell P and 59 others (2013) Bedmap2: improved ice bed, surface and thickness datasets for Antarctica. Cryosphere, 7(1), 375-393 (doi: 10.5194/tc-7-375-2013)

Gjermundsen E and 5 others (2011) Assessment of multispectral glacier mapping methods and derivation of glacier area changes, 19782002, in the central Southern Alps, New Zealand, from ASTER satellite data, field survey and existing inventory data. J. Glaciol., 57, 667-683 (doi: 10.3189/002214311797409749)

Herzfeld UC (2004) Atlas of Antarctica: topographic maps from Geostatistical analysis of satellite radar altimeter data. SpringerVerlag, Berlin, $364 \mathrm{p}$.

Herzfeld UC, Wallin BF, Leuschen CJ and Plummer J (2011) An algorithm for generalizing topography to grids while preserving subscale morphologic characteristics-creating a glacier bed DEM for Jakobshavn trough as low-resolution input for dynamic ice-sheet models. Comput. Geosci., 37(11), 17931801 (doi: 10.1016/j.cageo.2011.02.021)

Journel AG (1986) Geostatistics: models and tools for the earth sciences. Math. Geol., 18(1), 119-140 (doi: 10.1007/BF00897658)

Koppes M, Hallet B and Anderson J (2009) Synchronous acceleration of ice loss and glacial erosion, Glaciar Marinelli, Chilean Tierra del Fuego. J. Glaciol., 55(190), 207-220 (doi: 10.3189/ 002214309788608796)

Lapazaran J and 6 others (2013) Ice volume changes (1936-19902007) and ground-penetrating radar studies of Ariebreen, Hornsund, Spitsbergen. Pol. Res., 32, 11068 (doi: 10.3402/ polar.v32i0.11068)

Lapazaran JJ, Otero J, Martín-Español A and Navarro FJ (2016) On the errors involved in ice-thickness estimates I: ground-penetrating radar measurement errors. J. Glaciol. (doi: 10.1017/jog.2016.93)

Lindbäck K and 8 others (2014) High-resolution ice thickness and bed topography of a land-terminating section of the Greenland Ice Sheet. Earth Syst. Sci. Data, 6, 331-338 (doi: 10.5194/essd6-331-2014)

Martín-Español A and 7 others (2013) Radio-echo sounding and ice volume estimates of western Nordenskiöld Land glaciers, Svalbard. Ann. Glaciol., 54(64), 211-217 (doi: 10.3189/2013AoG64A109)

Martín-Español A, Lapazaran JJ, Otero J, Navarro FJ (2016) On the errors involved in ice-thickness estimates III: error in volume. J. Glaciol. (doi: 10.1017/jog.2016.95)

Morlighem M and 5 others (2011) A mass conservation approach for mapping glacier ice thickness. Geophys. Res. Lett., 38(19), L19503 (doi: 10.1029/2011GL048659)

Morlighem M and 6 others (2013) High-resolution bed topography mapping of Russell Glacier, Greenland, inferred from Operation IceBridge data. J. Glaciol., 59(218), 1015-1023 (doi: 10.3189/2013JoG12J235) 
Navarro FJ and 6 others (2014) Ice volume estimates from groundpenetrating radar surveys, Wedel Jarlsberg Land glaciers, Svalbard. Arct. Antarct. Alp. Res., 46(2), 394-406 (doi: 10.1657/1938-4246-46.2.394)

Nuth C and 7 others (2013) Decadal changes from a multi-temporal glacier inventory of Svalbard. Cryosphere, 7(5), 1603-1621 (doi: 10.5194/tc-7-1603-2013)

Otero J, Navarro FJ, Martín C, Cuadrado ML and Corcuera MI (2010) A three-dimensional calving model: numerical experiments on Johnsons Glacier, Livingston Island, Antarctica. J. Glaciol., 56 (196), 200-214 (doi: 10.3189/002214310791968539)

Paul F and 19 others (2013) On the accuracy of glacier outlines derived from remote sensing data. Ann. Glaciol., 54, 171-182 (doi: 10.3189/2013AoG63A296)

Pettersson R, Jansson P and Holmlund P (2003) Cold surface layer thinning on Storglaciären, Sweden, observed by repeated ground penetrating radar surveys. J. Geophys. Res., 108(F1), 6004 (doi: 10.1029/2003JF000024)

Pettersson R and 5 others (2011) Ice thickness and basal conditions of Vestfonna ice cap, eastern Svalbard. Geogr. Ann.: Ser. A Phys. Geog., 93(4), 311-322 (doi: 10.1111/j.1468-0459.2011.00438.x)

Pfeffer WT and 19 others (2014) The Randolph Glacier Inventory: a globally complete inventory of glaciers. J. Glaciol., 60(221), $537-$ 552 (doi: 10.3189/2014JoG13J176)
Rotschky G and 6 others (2007) A new surface accumulation map for western Dronning Maud Land, Antarctica, from interpolation of point measurements. J. Glaciol., 53(182), 385-398 (doi: 10.3189/002214307783258459)

Sugiyama S, Sakakibara D, Tsutaki S, Maruyama M and Sawagaki T (2015) Glacier dynamics near the calving front of Bowdoin Glacier, northwestern Greenland. J. Glaciol., 61(226), 223-232 (doi: 10.3189/2015JoG14J127)

Szidarovszky F, Baafi EY and Kim YC (1987) Kriging without negative weights. Math. Geol., 19(6), 549-559 (doi: 10.1007/ BF00896920)

Wackernagel H (2003) Multivariate geostatistics. An introduction with applications. 3rd completely revised edition, SpringerVerlag, Berlin, 388 p (doi: 10.1007/978-3-662-05294-5)

Welch BC, Pfeffer WT, Harper JT and Humphrey NF (1998) Mapping subglacial surfaces below temperate valley glaciers using 3dimensional radio-echo sounding techniques. J. Glaciol., 44 (146), 164-170

Wilkens $\mathrm{N}$ and 5 others (2015) Thermal structure and basal sliding parametrisation at Pine Island Glacier - a 3-D full-Stokes model study. Cryosphere, 9(2), 675-690 (doi: 10.5194/tc-9-675-2015)

Yamamoto JK (2000) An alternative measure of the reliability of ordinary kriging estimates. Math. Geol., 32(4), 489-509 (doi: 10.1023/A:1007577916868)

MS received 5 September 2015 and accepted in revised form 26 June 2016; first published online 30 September 2016 